Mariana dos Santos Ribeiro

\title{
Construindo Histórias e Memórias: O IHGB e - IAGP em meio às celebrações do centenário do movimento pernambucano de 1817
}

\section{Tese de Doutorado}

Tese apresentada ao Programa de Pós-graduação em História Social da Cultura da PUC-Rio como parte dos requisitos parciais para obtenção do título de Doutor em História.

Orientador: Prof. Marco Antonio Villela Pamplona

Rio de Janeiro 


\title{
Mariana dos Santos Ribeiro
}

\section{Construindo Histórias e Memórias: O IHGB e - IAGP em meio às celebrações do centenário do movimento pernambucano de 1817}

Tese apresentada como requisito parcial para obtenção do grau de Doutor pelo Programa de Pós-Graduação em História Social da Cultura do Departamento de História do Centro de Ciências Sociais da PUC-Rio. Aprovada pela Comissão Examinadora abaixo assinada.

\author{
Prof. Marco Antonio Villela Pamplona \\ Orientador \\ Departamento de História \\ PUC-Rio
}

Prof ${ }^{\text {a }}$ Márcia de Almeida Gonçalves

Departamento de História

UERJ

Prof. IImar Rohloff de Mattos Departamento de História

PUC-Rio

Prof ${ }^{\text {a }}$ Norma Côrtes Gouveia de Melo

Departamento de História

IFCS-UFRJ

Profa. Silvia Carla Pereira de Brito Fonseca

Departamento de História

UNIRIO

Prof ${ }^{\text {a. }}$ Mônica Herz

Vice-Decana de Pós-Graduação do Centro de Ciências Sociais

PUC-Rio

Rio de Janeiro, 13 de setembro de 2011. 
Todos os direitos reservados. É proibida a reprodução total ou parcial do trabalho sem autorização da universidade, da autora e do orientador

\section{Mariana dos Santos Ribeiro}

Graduou-se em História na UERJ (Universidade do Estado do Rio de Janeiro). Fez Pós-Graduação Lato Sensu em História do Brasil pela UCAM (Universidade Cândido Mendes) e Mestrado em História Política pela UERJ. Participou de diversos congressos na área de História

Ficha Catalográfica

Ribeiro, Mariana dos Santos

Construindo histórias e memórias : o IHGB e o IAGP em meio às celebrações do centenário do movimento pernambucano de 1817 / Mariana dos Santos Ribeiro ; orientador: Marco Antonio Villela Pamplona. -2011.

298 f. ; $30 \mathrm{~cm}$

Tese (doutorado)-Pontifícia Universidade Católica do Rio de Janeiro, Departamento de História, 2011.

Inclui bibliografia

1. História - Teses. 2. Narrativas nacionais. 3. História. 4. Memória. 5. IHGB. 6. IAGP. 7. Movimento pernambucano de 1817. 8. Primeira república brasileira. I. Pamplona, Marco Antônio. II. Pontifícia Universidade Católica do Rio de Janeiro. Departamento de História. III. Título.

CDD: 900 


\section{Agradecimentos}

Para a elaboração desta tese, recebi ajuda de muitas pessoas, que contribuíram através suas sugestões, apoio, incentivo ou informações importantes.

Em primeiro lugar, agradeço ao Programa de Pós-Graduação em História Social da Cultura da Puc-Rio, por ter acolhido a minha proposta inicial de trabalho.

Agradeço também à Capes, Coordenação de Aperfeiçoamento de Pessoal de Nível Superior, pela concessão da bolsa de incentivo à pesquisa, o que permitiu dedicação exclusiva ao trabalho durante boa parte do curso.

Aos professores do Programa, em especial à Margarida de Souza Neves e a Luiz Costa Lima, que, através de suas disciplinas, muito contribuíram com orientações e sugestões importantes.

Gostaria de fazer um agradecimento especial ao meu orientador, professor Marco Antonio Villela Pamplona, por ter me aceitado como sua orientanda, e por ter sido sempre atencioso e solícito em todos os momentos, mesmo naqueles mais difíceis.

Gostaria de agradecer também aos professores que participaram da minha banca de qualificação, Ilmar R. de Mattos e Silvia Carla Fonseca, pelas preciosas sugestões, delicadeza e simpatia com que procederam suas observações e críticas.

Agradeço também às professoras Norma Côrtes e Maria Emília Prado pelo incentivo na época da seleção para o ingresso no curso de Doutorado.

Aos funcionários que me atenderam no Instituto Histórico e Geográfico Brasileiro, sempre gentis e atenciosos a todas as minhas solicitações.

Aos funcionários da secretaria de História da Puc-Rio, em especial a Edna Timbó, sempre dedicada e prestativa.

Em especial, gostaria de agradecer à Sônia Regina Vieira do Nascimento Rodrigues, por seu empenho e versatilidade, contribuindo há anos com funcionamento da minha casa.

À Josefa Marluse de Jesus Oliveira, à Ana Paula da Silva Farias e a todos da equipe da Creche e Escola Tempo Mágico, pelo carinho, atenção e os cuidados com o meu filho Lucas. Sem a dedicação dessas pessoas, a conclusão desse trabalho, definitivamente, não seria possível. 
A toda a minha família, especialmente aos meus pais, por sempre terem acreditado na importância da minha educação, apesar de todas as adversidades da vida.

À minha irmã, Maria Clara dos Santos Ribeiro, por sempre cumprir tão bem o seu papel e, por tantas vezes, também ter cumprido o meu.

A Victor Leite Borges de Souza, sempre solícito e gentil ao ter me ajudado diversas vezes com a entrega de livros na biblioteca e documentos importantes na secretaria de História da Puc-Rio.

Por fim, gostaria de fazer um agradecimento todo especial ao meu esposo, Rodrigo Pereira da Silva, pelo apoio incondicional e por estar sempre ao meu lado em todos os momentos importantes da minha vida. Obrigada por você existir!

A todos, os meus sinceros agradecimentos. 


\section{Resumo}

Ribeiro, Mariana dos Santos; Pamplona, Marco Antonio Villela. Construindo histórias e memórias: O IHGB e o IAGP em meio às celebrações do movimento pernambucano de 1817. Rio de Janeiro, 2011. 298p. Tese de Doutorado - Departamento de História, Pontifícia Universidade Católica do Rio de Janeiro

Esta tese tem por objetivo analisar o processo de construção das narrativas nacionais produzidas em dois institutos de história e memória: o Instituto Histórico e Geográfico Brasileiro (IHGB) e o Instituto Arqueológico e Geográfico Pernambucano (IAGP), atualmente, Instituto Arqueológico Histórico e Geográfico Pernambucano (IAHGP). Tem como principal pano de fundo, os discursos produzidos por membros dessas duas instituições, no contexto de comemoração do centenário do movimento pernambucano de 1817. A idéia é compreender os novos usos políticos que se fazia do passado, bem como as tensões e intenções que norteavam a historiografia desses Institutos, em pleno contexto de afirmação dos valores cívicos republicanos. Em uma perspectiva mais ampla, pretende-se compreender como foram construídos os principais mitos políticos na Primeira República brasileira.

\section{Palavras-chave}

Narrativas Nacionais; História; Memória; IHGB; IAGP; Movimento Pernambucano de 1817; Primeira República Brasileira. 


\section{Abstract}

Ribeiro, Mariana dos Santos; Pamplona, Marco Antonio Villela (Advisor). Making up History and Memories: The IHGB and the IAGP at the time of the hundredth-anniversary celebrations of the Pernambuco 1817 revolt. Rio de Janeiro, 2011. 298p. Doctoral Thesis - Departamento de História, Pontifícia Universidade Católica do Rio de Janeiro

My purpose with this thesis is to analyze the construction of national narratives produced by two early institutions dedicated to history making and the building of memory: the Brazilian Historical and Geographical Institute and the Archeological Geographical Institute of the State of Pernambuco, currently the Archeological, Historical Geographical Institute of the State of Pernambuco. I deal mainly with the discourses the the members of both institutions produced at the time of the hundreth anniversary celebrations of the Pernambuco 1817 revolt. I intend to understand the new political uses that were made concerning the past, as well as to unveil the conflicts and intentions that had driven the historiography of both institutes, at the time of consolidation of the republic. My goal is to understand how some of the main political myths in the Brazilian First Republic were constructed.

\section{Keywords}

National Narrative; History; Memory; IHGB; IAGP; Pernambuco 1817 Revolt, Brazilian First Republic. 


\section{Sumário}

Introdução

1 Revisitando o passado em tempos de conturbação

política, econômica e social

1.1. As comemorações do centenário da Insurreição

Pernambucana de 1817

1.2. Memória, história e historiografia: algumas

considerações importantes

2 Instituto Histórico e Geográfico Brasileiro e Instituto

Arqueológico e Geográfico Pernambucano-dois espaços

de construção de memória e história

2.1. IHGB: lócus tradicional de construção da memória nacional

2.2. A historiografia do IHGB e seu papel crucial no projeto de construção nacional

2.3. O IHGB entre metamorfoses e permanências:

as novas narrativas nacionais em tempos de República

2.4. Pátria, Religião e Liberdade: O IAGP e as suas

novas "versões" para as narrativas nacionais

2.5. Movimentos pernambucanos versus Conjuração

Mineira. A guerra pela representação da memória republicana

3 O IHGB, o IAGP e as comemorações do centenário da República de 1817 
3.1. O IHGB e os Institutos Históricos e

Geográficos locais: algumas dissensões importantes

3.1.1. Os Institutos Históricos de São Paulo e de Minas Gerais

3.2. IHGB e IAGP: semelhanças e diferenças na representação dos eventos pernambucanos

3.3. As comemorações dos cem anos de 1817

4 Conclusão 


\section{Abreviaturas}

APM: Arquivo Público Mineiro

IAGP: Instituto Arqueológico e Geográfico Pernambucano

IAHGP: Instituto Arqueológico, Histórico e Geográfico Pernambucano

IHGB: Instituto Histórico e Geográfico Brasileiro

IHGMG: Instituto Histórico e Geográfico de Minas Gerais

IHGPB:Instituto Histórico e Geográfico Paraibano

IHGRN: Instituto Histórico e Geográfico do Rio Grande do Norte

IHGSP: Instituto Histórico e Geográfico de São Paulo

RAPM: Revista do Arquivo Público Mineiro

RIAGP: Revista do Instituto Arqueológico, Histórico e Geográfico Pernambucano

RIHGB: Revista do Instituto Histórico e Geográfico Brasileiro

RIHGSP: Revista do Instituto Histórico e Geográfico de São Paulo 
"Tornar-se senhores da memória e do esquecimento é uma das grandes preocupações das classes, dos grupos, dos indivíduos que dominarame dominam as sociedades históricas" 